\title{
Detection of myelin autoantibodies: evaluation of an assay system for diagnosis of multiple sclerosis in differentiation from other central nervous system diseases
}

\author{
Markus Langkamp ${ }^{1, *}$, Stephanie C. Hörnig ${ }^{2}$, \\ Joachim B. Hörnig ${ }^{2}$, Marion Kirschner ${ }^{1}$, Lutz \\ Pridzun $^{1}$ and Malte E. Kornhuber ${ }^{3}$ \\ ${ }^{1}$ Mediagnost Gesellschaft für Forschung und \\ Herstellung von Diagnostika GmbH, Reutlingen, \\ Germany \\ ${ }^{2}$ Gesellschaft zur Förderung von Medizin-, Bio-, \\ und Umwelttechnologien e.V., Fachsektion Halle \\ Halle (Saale), Germany \\ ${ }^{3}$ Martin-Luther Universität Halle-Wittenberg, \\ Universitätsklinik und Poliklinik für Neurologie, \\ Halle (Saale), Germany
}

\begin{abstract}
Background: Multiple sclerosis (MS) is a frequent and often severe autoimmune disease of the central nervous system. We describe a newly developed enzymelinked immunosorbent assay (ELISA)-based test system for the assessment of neuronal autoantibodies in serum and cerebrospinal fluid (CSF). This tool could help define autoimmune status and thus be a potential means of therapeutic surveillance.

Methods: We used an assay system (ELISA, E100, Mediagnost) based on purified bovine antigens [myelin-oligodendrocyte glycoprotein (MOG), myelin basic protein (MBP), myelin-associated glycoprotein (MAG), proteolipid protein (PLP) and alpha-B-crystalline (CRY) antibodies for the measurement of specific immunoglobulin $\mathrm{G}(\mathrm{IgG})$ and immunoglobulin $M$ (IgM) antibodies. Assay characteristics and preliminary validation were conducted by measurement of serum and CSF samples from $41 \mathrm{MS}$ patients and 128 patients with other neurological diseases (OND).

Results: We measured the inter- $(17.8 / 10.1 \%)$ and intra-assay variability (5.5/6.7\%); linearity (1:250$1: 16,000)$, and specificity of $\lg$ and $\lg M$. We demonstrate that by the results of this test system MS patients can be differentiated from patients with OND. Conclusions: The ELISA kit we evaluated is suitable for the measurement of neuronal autoantibodies. The initial validation demonstrates its potential use in the differential diagnosis of central neuronal system diseases.
\end{abstract}

Clin Chem Lab Med 2009;47:1395-400.

Keywords: autoantibody; ELISA; multiple sclerosis; myelin antigen; neuronal antigen.

*Corresponding author: Markus Langkamp, Mediagnost $\mathrm{GmbH}$, Aspenhaustr. 25, 72770 Reutlingen, Germany Phone: + 49712151484 0, Fax: +49712151 484 10, E-mail: langkamp@mediagnost.de Received May 28, 2009; accepted July 28, 2009

\section{Introduction}

T-cell mediated autoimmunity is a hallmark of the pathogenesis of multiple sclerosis (MS) $(1,2)$. Possibly, autoreactive $\mathrm{CD} 4^{+} \mathrm{T}$-cells, activated by an external stimulus, such as viral infections, initiate the demyelinating process (1). The relevance of B-cells has long been questioned because myelin-specific antibodies are not able to induce MS in animal models. But the presence of autochthonously synthesised antibodies in the cerebrospinal fluid (CSF) of MS patients is well known, and detection of oligoclonal bands is of diagnostic importance (3-5). Therefore, it is assumed that the degree of central nervous tissue injury is influenced by the amount of antibodies (6). Thus, B-cells in addition to T-cells, may take part in tissue damage in MS. Recently, the relevance of Bcells in MS pathology has been proven by new therapeutic strategies, such as the use of monoclonal antibodies (e.g., rituximab) that target B-cells and eliminate them from the circulation. In clinical studies, MS patients treated with rituximab had significantly less inflammatory brain lesions and less clinical relapses compared to the control group treated with placebo $(7,8)$. As a result, antibody producing B-cells are now the focus of MS research.

The increase in CSF antibody concentrations is caused by clonal, B-cell driven intrathecal antibody synthesis (9). However, this is not specific for MS. Several studies have investigated the diagnostic value of autoantibodies against myelin proteins by Western blot, enzyme-linked immunosorbent assay (ELISA) or flow cytometry (10), employing recombinant, natural purified or peptide antigens. The results are somewhat contradictory. Some studies show the relevance of antibodies against myelin basic protein (MBP), while others do not $(11,12)$. Similarly inconsistent results have been obtained for myelin proteolipid protein (PLP), myelin-associated glycoprotein (MAG), and myelin oligodendrocyte glycoprotein (MOG) (12-17). These contradictory results may partially be explained by differences in methodologies. In addition, measurement of only one or two autoantibody titres may not be sufficient for diagnostic purposes.

The present study shows data on the first test system using a combination of purified bovine MAG, MBP, MOG, PLP and alpha-B-crystalline (CRY) as antigenic materials. These five antigens were included in order to facilitate the direct and simultaneous comparison of reactions against autoantigens in MS and other neurological diseases (OND). 
In the present study, we focus on the technical evaluation of immunoglobulin $\mathrm{G}(\mathrm{lgG})$ and immunoglobulin ( $\operatorname{gM} \mathrm{M})$ measurements. We present data on reproducibility, sensitivity, linearity, and interference. Also, we investigated a small group of MS patients with corresponding serum and CSF samples and compared these to patients with non-MS neurological diseases.

\section{Materials and methods}

Chemical reagents were purchased from Merck (Darmstadt, Germany) or Sigma-Aldrich (Munich, Germany).

\section{Patients}

The diagnosis of MS was defined clinically and supported by laboratory data according to the internationally accepted McDonald criteria (18). Only MS patients with a chronic progressive form of MS and without signs of any OND were included. Forty-one patients with MS met the inclusion criteria. Of these, 36 showed secondary progressive disease course, while five patients were progressive from the onset.

We also included 128 patients with OND as the control group. The following diseases were present in the control group (patient numbers are given in brackets): spinal canal stenosis $(n=7)$, idiopathic facial nerve paresis $(n=8)$, cerebral inflammation $(n=46)$ ischaemic stroke $(n=12)$, vascular dementia $(n=11)$, various types of polyneuropathies $(n=20)$ and further OND $(n=24)$. Patients with suspicion or evidence of MS were excluded from the OND group.

\section{Serum and CSF samples}

CSF and serum samples were obtained from the routine laboratory of the Neurologische Klinik and Poliklinik of the Martin-Luther-Universität Halle-Wittenberg and from Neurologische Klinik of Krankenhaus Martha-Maria Halle-Dölau. Paired CSF and serum specimens were obtained from each patient and stored frozen at $-20^{\circ} \mathrm{C}$ until use, within 24 months. The CSF and serum samples had been used for routine diagnosis. Albumin, total IgG and IgM content were quantitated using standard immunochemical nephelometry.

\section{Ethics}

The study was performed in accordance with the Declaration of Helsinki Ethical Guidelines and was approved by the Ethics Committee of the Martin-Luther University Halle-Wittenberg, Germany.

\section{ELISA}

The ELISA (E100) for the detection of neuronal autoantibodies was developed by Mediagnost, Germany using a serum internal standard pool for calculation of antibody titres and employing microplates coated with purified bovine MAG, MOG, MBP, PLP and CRY. The assay was conducted according to the manufacturer's instructions (Mediagnost, Reutlingen Germany). Briefly, $100 \mu \mathrm{L}$ of diluted serum or CSF was pipetted into each well of the microtitre plate and incubated under agitation at $350 \mathrm{rpm}$ for $2 \mathrm{~h}$ at room temperature. The biotinylated detection antibody and horseradish-peroxidase streptavidin-conjugate were added sequentially. Each was incubated for $60 \mathrm{~min}$ at room temperature. After the addition of substrate and stop solution, the optical density was measured at $450 \mathrm{~nm}$. The arbitrary antibody amounts were calculated using extinctions of a standard serum included in the testkit.

\section{Data transformation and index calculation}

Specific antibody content was measured for 41 paired serum and CSF samples of MS patients and 128 paired samples of OND patients. Additionally, total IgG and IgM content were determined in serum and CSF by routine methods. For statistical analysis, the relative amount of specific $\lg G$ and $\lg M$ antibody was calculated for each antigen in serum and CSF separately according to the following formula:

$$
\frac{s A-l g}{\operatorname{tg}}=\text { relative } \cdot s A-l g
$$

sA-Ig, antigen-specific $\lg G$ or $\lg M$ antibody concentration in CSF or serum; tlg, total IgG or IgM antibody concentration $[\mathrm{g} / \mathrm{L}]$ in CSF or serum.

In a second step, the quotient of specific $\mathrm{lgG} / \mathrm{lgM}$ in CSF and serum was calculated for each antigen separately:

${ }^{\operatorname{CSF}}\left[\frac{s A-l g}{t / g}\right] \times{ }^{\text {Serum }}\left[\frac{s A-l g}{t l g}\right]^{-1}=s A-$ Index

\section{Statistical analysis}

All statistical analyses were conducted by using SPSS for Windows Version 11.0.0 (2001, Chicago, IL, USA). Beside descriptive statistics for calculation of the mean and standard deviation (SD) for each antigen (Table 2), the main focus was the analysis of differences between the CSFserum quotients in two groups, the MS patients and the OND patients. Significance level was set to $\alpha=0.05$. Tested hypothesis $\left(\mathrm{H}_{0}\right)$ was:

1. no differences between the specific antibody content of serum and CSF in patients with MS or OND could be detected, and

2. no difference between the specific antibody index of patients with MS or OND could be detected.

Analysis of variance was used to detect significant differences between the mean of the two groups for specific IgG and IgM in serum and CSF antigen as well as for the IgG and IgM sA-Index.

\section{Results}

\section{Precision and reproducibility}

The characteristics of the applied assay are shown in Table 1. Inter-assay variability was tested by doing at least five measurements of three different serum samples on different occasions. On average the mean relative coefficients of variation (CV) for inter-assay variance of $\lg$ and IgM antibody titres against MOG, MBP, MAG, PLP and CRY were 12\% (SD 4.7) and 14\% (SD 1.5), respectively. To assess the intra-assay variance, serum samples were measured at least 6 times in the same assay. The resulting CVs in the case of 
Table 1 Precision and reproducibility.

\begin{tabular}{lrrrr}
\hline & MOG & MBP & MAG & PLP \\
\hline Inter-assay IgG mean, \%CV & 13.77 & 7.17 & 10.75 & 17.47 \\
SD inter-assay IgG SD & 6.61 & 1.94 & 6.70 & 3.84 \\
Inter-assay IgM mean, \%CV & 14.84 & 12.74 & 14.07 & 3.30 \\
SD inter-assay IgM SD & 2.87 & 6.36 & 3.11 & 4.17 \\
Intra-assay IgG Mean, \%CV & 3.94 & 3.76 & 7.43 & 3.19 \\
SD intra-assay IgG SD & 1.83 & 1.49 & 3.20 & 8.42 \\
Intra-assay IgM mean, \%CV & 4.66 & 3.95 & 11.35 & 5.82 \\
Intra-assay IgM SD & 2.59 & 2.58 & 2.93 & 6.31 \\
\hline
\end{tabular}

Inter-assay variability was tested by doing five measurements of three different serum samples and for intra-assay variance, serum samples were measured 6 times in the same assay. The mean \%CV and SD of the three samples is shown here.

$\lg G$ and $\lg M$ measurements were on average $5.5 \%$ (SD 2.0) and 6.6\% (SD 2.3), respectively.

\section{Analytical sensitivity and accuracy}

For investigation of analytical sensitivity, we measured 14 zero samples (blank) and thus calculated mean and SD. The analytical sensitivities, defined as the mean antibody titre of the zero sample $+3 \mathrm{SD}$, were $0.3,0.48,0.21,0.11$ and 0.61 arbitrary titre units for $\lg \mathrm{G}$ measurement and 1.68, 0.54, 0.34, 2.4, 0.76 in the case of IgM for MOG, MBP, MAG, PLP and CRY, respectively.

Linearity is shown in a representative specimen in Figure 1. An exemplary serum sample was diluted from $1: 1000$ up to $1: 16,000(\mathrm{lgG})$ and $1: 250$ up to 1:3000 (IgM). In Figure 1, the resulting optical densities of each dilution are shown and analysed by linear regression analysis, demonstrating a high degree of linearity.

\section{Interference}

Interference and cross-reactivity of the assay were tested by either adding triglycerides (Institute for Reference Materials and Measurements, Geel, Belgium) or bilirubin (Sigma-Aldrich, Munich, Germany) in various concentrations to a serum sample. Neither bilirubin (up to $200 \mathrm{mg} / \mathrm{L} ; 0.342 \mathrm{mmol} / \mathrm{L}$ ) nor triglycerides (up to $200 \mathrm{~g} / \mathrm{L}$ ) interfered significantly with the measurement of MOG, MAG and CRY antibody titres. Determination of MBP antibody titre was significantly influenced by both substances, in the case of PLP the measurement of $\lg M$ antibodies was also influenced by triglycerides as well as by bilirubin.

\section{Specificity}

Specificity of bound antibodies was investigated by the use of soluble antigen for competitive binding. Results are shown in Figure 2. The addition of control material, bovine serum albumin (BSA), did not result in significant reduction of antibody binding. In the case of MOG, MAG, and CRY addition of antigenic material resulted in a concentration dependent reduction of $\lg G$ and $\lg M$ binding. Antibody binding to MBP and PLP could not be inhibited by incubation of the sample with antigen.

\section{Preliminary validation}

Exemplarily, the capability of the described assay to discriminate between MS and OND was investigated. Assuming that each kind of antibody is produced by a pool of different B-cells, the measured values were seen as independent results. Furthermore, each patient sample can be regarded as a source of independent antibody titre values. Thus, an analysis of variance was used to evaluate whether significant differences between the means of each group exist. Significant differences ( $p$-values in parentheses) were
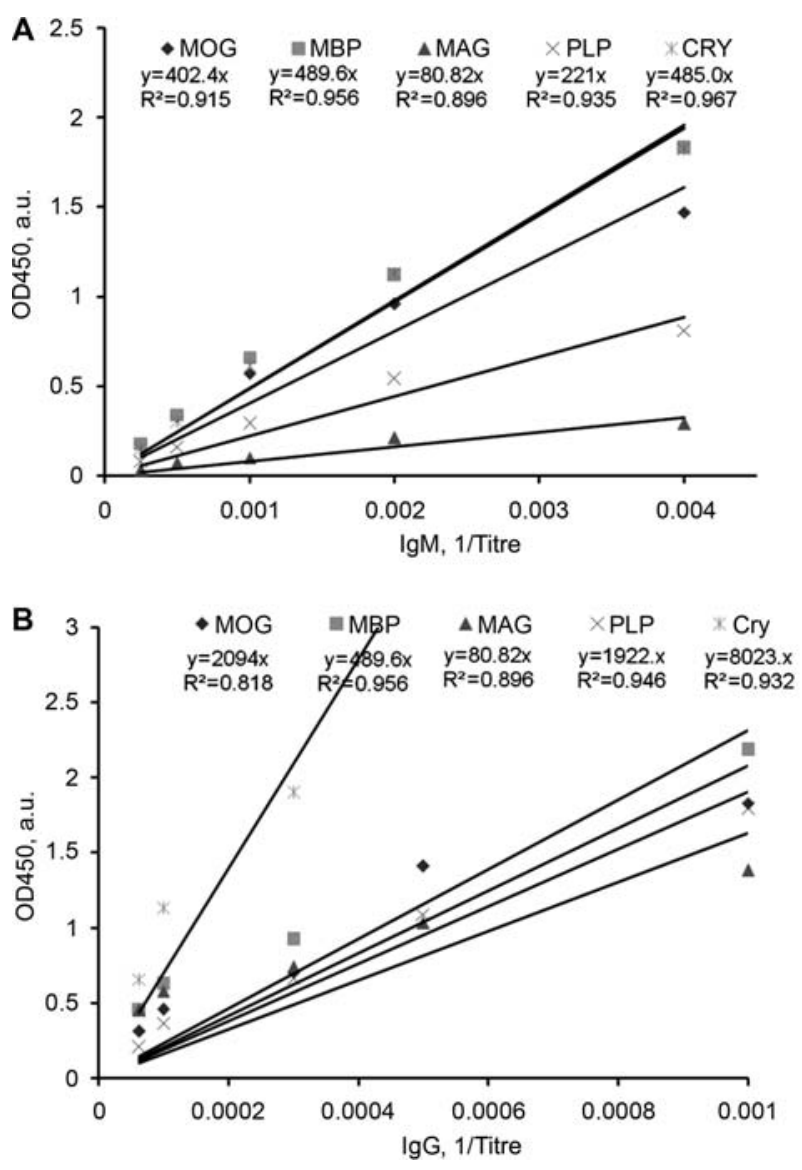

Figure 1 Linearity of sample dilution of a representative sample.

The arbitrary optical densities for each dilution of IgM (A) and IgG (B) are shown. Data were analysed by linear regression, resulting equations and correlation factors are shown. 


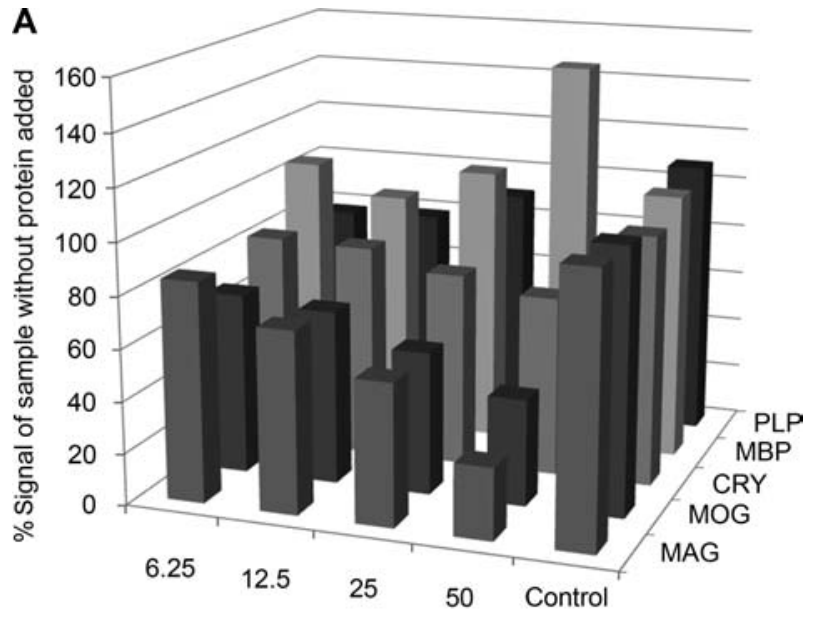

Added amount of protein, $\mathrm{mg} / \mathrm{L}$

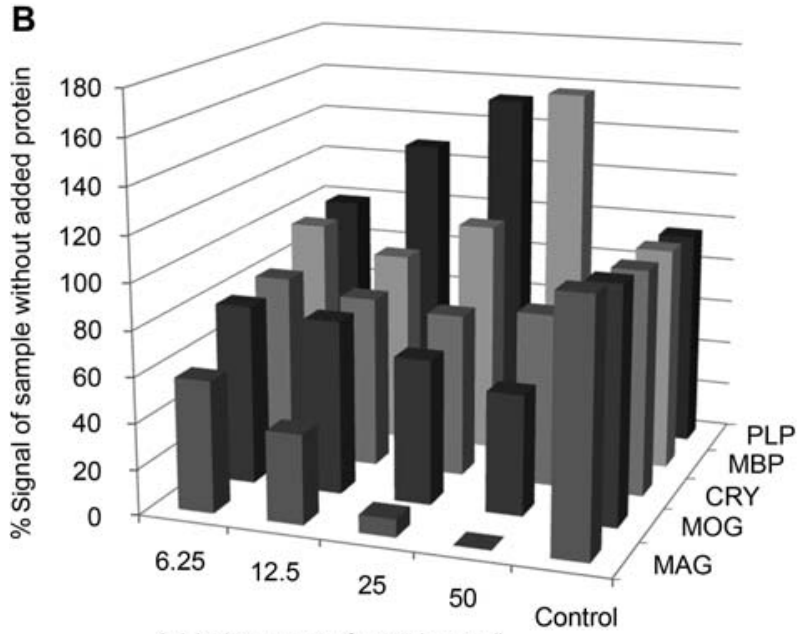

Added amount of protein, $\mathrm{mg} / \mathrm{L}$

Figure 2 Binding competition by preincubation with antigen material.

Samples were diluted (1:500) in dilution buffer containing indicated concentrations of protein. Shown is the relative binding of $\lg M(A)$ and $\lg G(B)$ antibodies in comparison to negative control.

detected for the anti-MAG-IgG in serum (0.028) and anti-MAG IgM in CSF (0.045), only. Additionally, for two sA-Indices, a significant difference between the two groups was detected: IgG-PLP (0.008) and IgMPLP (0.04). Detailed ANOVA results obtained for the amount of specific antibody as well as for the specific antibody indices (CSF/serum) are shown in Table 2A and 2B.

\section{Discussion}

Beside T-cell mediated neuronal destruction, also Bcells and B-cell produced antibodies seem to be of functional relevance in the pathogenesis of MS (19). Therefore, an assay system for the detection of specific anti-myelin IgG or IgM antibodies may be of use to study abnormalities of the humoral immune regulation in MS. The assay that is characterised here employs bovine MOG, MAG, MBP, PLP and CRY as antigenic materials for the simultaneous detection of antibodies against all these antigens. Thus, we assume that a reliable multidimensional test in connection with statistical analysis will be able to detect small changes in the immune status of the patient. This may be of relevance for understanding the pathogenesis of this inflammatory CNS disease. Furthermore, myelin autoantibody detection may be useful to monitor the dynamics of neuro-inflammation and thus may eventually be of therapeutic relevance.

Precision and reproducibility of the ELISA-based commercial assay detecting five specific neuronal autoantibodies in human serum and CSF revealed on average for $\lg 5.5 \%$ and $11.7 \%$, and $\lg M 6.3 \%$ and $14.3 \%$. These values are within an acceptable range for immunoassays measuring autoantibodies $(20,21)$. Furthermore, sensitivity and linearity (Figure 1) are excellent. Bilirubin and triglycerides interfere in MBP and PLP measurements. Thus, lipaemic or icteric samples cannot be used for this assay.

Further, the specificity of the assay system was tested by antigen competition. The control (BSA) does not influence the binding of IgG antibodies, but a preincubation of the diluted sample together with antigen results in a concentration dependent decrease of antibody binding. Only in the case of MBP and PLP such a concentration dependent decrease could not be shown. Here, even an increase in antibody binding was detected (Figure 2). Analysis of amino acid sequence of PLP and MBP reveals that in comparison to MOG, MAG, and CRY, PLP contains four transmembrane domains, more than the other proteins $(22,23)$. MBP is a soluble, membrane-associated protein but it is well known that the protein is able to interact with itself and with other proteins $(24,25)$. Thus, we assume that the limited success in competition of antibody binding eventually does not reflect non-specific binding but rather results from biochemical properties of the antigen.

The preliminary clinical validation demonstrates that patients with MS can be differentiated from patients with OND. The distinction was based on the measured amount of antibodies against a single antigen present in serum and/or CSF. Although only a relatively small group of MS patients with primary or secondary progressive MS was included into the study, this assay seems to be a suitable tool for discriminating between MS and OND on the basis of autoantibodies in serum and CSF. Contradictory to current pathogenetic concepts of MS, the CSF/serum specific antibody index (sA-Index) against myelin antigens was found to be significantly decreased in MS patients compared to patients with OND, if a significant difference has been detected at all. This is also reflected in the amount of MAG-specific antibody in serum and CSF. MS patients have significantly more anti-MAG antibodies in serum but less in CSF compared with OND patients. One possible reason for this result may be the presence of patients with inflammatory diseases, such as meningitis in the OND group. Furthermore, in neurodegeneration such as stroke or vascular dementia, secondary autoimmune phenomena might be of pathogenetic relevance. Rea- 
Table 2A Statistics.

\begin{tabular}{|c|c|c|c|c|c|c|c|}
\hline MS patients & $\mathrm{n}$ & Mean & SD & OND patients & $\mathrm{n}$ & Mean & SD \\
\hline \multicolumn{8}{|l|}{ Serum } \\
\hline $\operatorname{lgG} \mathrm{MBP}$ & 41 & 0.092 & 0.05 & IgG MBP & 127 & 0.095 & 0.11 \\
\hline IgG MOG & 41 & 0.106 & 0.06 & $\operatorname{lgG}$ MOG & 128 & 0.109 & 0.07 \\
\hline $\lg G \mathrm{CRY}$ & 41 & 0.106 & 0.06 & $\lg G \mathrm{CRY}$ & 128 & 0.101 & 0.04 \\
\hline IgG MAG & 41 & 0.093 & 0.05 & $\operatorname{Ig} G$ MAG & 128 & 0.072 & 0.05 \\
\hline $\lg G$ PLP & 41 & 0.066 & 0.03 & IgG PLP & 128 & 0.064 & 0.07 \\
\hline $\operatorname{lgM}$ MBP & 41 & 1.548 & 0.88 & $\lg M$ MBP & 128 & 1.509 & 1.45 \\
\hline $\lg M$ MOG & 41 & 1.797 & 1.19 & $\lg M$ MOG & 128 & 1.993 & 2.72 \\
\hline IgM CRY & 41 & 1.912 & 1.15 & $\lg M$ CRY & 128 & 1.783 & 2.00 \\
\hline IgM MAG & 41 & 0.498 & 0.34 & $\operatorname{IgM}$ MAG & 128 & 0.541 & 0.70 \\
\hline IgM PLP & 41 & 0.339 & 0.3 & IgM PLP & 128 & 0.38 & 0.75 \\
\hline \multicolumn{8}{|c|}{ Cerebrospinal fluid } \\
\hline IgG MBP & 41 & 37.44 & 23.09 & IgG MBP & 128 & 29.3 & 25.56 \\
\hline IgG MOG & 41 & 4.31 & 5.31 & $\operatorname{lgG} \mathrm{MOG}$ & 128 & 4.70 & 8.11 \\
\hline IgG CRY & 41 & 7.33 & 4.4 & $\lg G \mathrm{CRY}$ & 128 & 7.42 & 10.23 \\
\hline $\operatorname{lgG}$ MAG & 41 & 3.46 & 2.82 & $\operatorname{lgG}$ MAG & 128 & 4.01 & 9.70 \\
\hline IgG PLP & 41 & 2.88 & 2.83 & IgG PLP & 128 & 5.57 & 15.63 \\
\hline $\lg M$ MBP & 41 & 1499 & 1460 & $\lg M$ MBP & 128 & 1079 & 1367 \\
\hline $\lg M$ MOG & 41 & 38.23 & 155.25 & $\lg M$ MOG & 128 & 120.4 & 374.0 \\
\hline IgM CRY & 41 & 67.78 & 102.46 & $\lg M$ CRY & 122 & 125.98 & 242.15 \\
\hline IgM MAG & 41 & 16.69 & 25.32 & IgM MAG & 128 & 74.47 & 170.18 \\
\hline IgM PLP & 41 & 29.85 & 36.02 & IgM PLP & 128 & 124.71 & 448.8 \\
\hline
\end{tabular}

Relative amount of antigen-specific $\lg G$ and $\operatorname{lgM}$ of multiple sclerosis patients (MS) and patients with other neurological diseases (OND). Significant difference between both groups is shown by bold italic letters.

Table 2B Statistics.

\begin{tabular}{|c|c|c|c|c|c|c|c|}
\hline MS patients & $\mathrm{n}$ & Mean & SD & OND patients & $\mathrm{n}$ & Mean & SD \\
\hline $\lg \mathrm{MBP}$ & 40 & 752 & 1731 & $\operatorname{lgg} \mathrm{MBP}$ & 120 & 669 & 1450 \\
\hline $\lg$ MOG & 41 & 49 & 70 & $\lg \mathrm{MOG}$ & 121 & 47 & 56 \\
\hline IgG CRY & 41 & 79 & 45 & $\lg G \mathrm{CRY}$ & 122 & 81 & 112 \\
\hline $\lg$ MAG & 41 & 36 & 23 & $\lg \mathrm{MAG}$ & 117 & 53 & 57 \\
\hline IgG PLP & 40 & 42 & 33 & IgG PLP & 115 & 76 & 78 \\
\hline IgM MBP & 41 & 1068 & 897 & $\lg M$ MBP & 122 & 1994 & 11,115 \\
\hline $\lg M$ MOG & 41 & 24 & 96 & $\operatorname{lgM}$ MOG & 122 & 103 & 360 \\
\hline $\lg M$ CRY & 41 & 49 & 76 & $\lg M$ CRY & 122 & 102 & 240 \\
\hline $\lg M$ MAG & 41 & 49 & 92 & $\lg M$ MAG & 121 & 155 & 340 \\
\hline IgM PLP & 41 & 127 & 183 & IgM PLP & 113 & 369 & 723 \\
\hline $\lg G$ SUM & 41 & 937 & 1717 & IgG SUM & 128 & 1018 & 2132 \\
\hline IgM SUM & 41 & 1317 & 970 & IgM SUM & 128 & 2774 & 11,681 \\
\hline
\end{tabular}

IgG and IgM sA-Index (CSF/serum) of multiple sclerosis patients (MS) and patients with other neurological diseases (OND). The indices that differ significantly between both groups are marked by bold italic letters.

sons for a decreased sA-Index in MS may, however, also concern the selection of MS patients. Thus, in secondary progressive MS, inflammation may be less prominent than in cases with a relapsing-remitting type of course. Furthermore, in cases with a progressive course from onset, neuro-inflammation may be even less prominent than in patients with secondary progression. Actually, only cases with progressive types of MS course were included into the present investigation, a fact that may partially account for the obtained result.

We finally conclude that the commercial Mediagnost ELISA E100 is a reliable assay for the measurement of human antibodies against MOG, MBP, MAG, PLP and CRY. The assay may be especially suited for the investigation of anti-myelin autoimmune responses in primary inflammatory diseases of the central nervous system, such as MS. However, it might also give worthful information on secondary antimye- lin autoimmune responses in primary degenerative diseases of the central nervous system, such as e.g., Alzheimer's disease or motor neuron disorders.

\section{Conflict of interest statement}

The following authors are employed by Mediagnost $\mathrm{GmbH}$ : Langkamp, Kirschner and Pridzun. No other conflict of interest is known.

\section{Acknowledgements}

We would like to thank Mathias Luck (GMBU e.V., Halle, Germany) for his excellent technical assistance. Further, we are grateful to the Bundesministerium für Wirtschaft und Technologie for supporting this work by the following grant: AIF II FKZ KF0035308MD5, the non-profit organization GMBU e.V. and the company Mediagnost $\mathrm{GmbH}$. 


\section{References}

1. Sospedra M, Martin R. Immunology of multiple sclerosis. Annu Rev Immunol 2005;23:683-747.

2. Confavreux C, Vukusic S. Natural history of multiple sclerosis: implications for counselling and therapy. Curr Opin Neurol 2002;15:257-66.

3. Compston A, Coles A. Multiple sclerosis. Lancet 2008; 372:1502-17.

4. Owens GP, Bennett JL, Lassmann H, O'Connor KC, Ritchie AM, Shearer A, et al. Antibodies produced by clonally expanded plasma cells in multiple sclerosis cerebrospinal fluid. Ann Neurol 2009;65:639-49.

5. Luxton RW, Zeman A, Holzel H, Harvey P, Wilson J, Kocen R, et al. Affinity of antigen-specific IgG distinguishesmultiple sclerosis from encephalitis. J Neurol Sci 1995; 132:11-9.

6. Aboul-Enein $F$, Bauer J, Klein M, Schubart A, Flügel A, Ritter $T$, et al. Selective and antigen-dependent effect of myelin degeneration on central nervous system inflammation. J Neuropathol Exp Neurol 2004;63:1284-96.

7. Link H. Bedside to bench: betting on $B$ cells in multiple sclerosis. Nat Med 2008;14:615-6.

8. Franciotta D, Salvetti M, Lolli F, Serafini B, Aloisi F. B cells and multiple sclerosis. Lancet Neurol 2008;7:852-8.

9. Obermeier B, Mentele R, Malotka J, Kellermann J, Kumpfel T, Wekerle $\mathrm{H}$, et al. Matching of oligoclonal immunoglobulin transcriptomes and proteomes of cerebrospinal fluid in multiple sclerosis. Nat Med 2008;14: 688-93.

10. Lily O, Palace J, Vincent A. Serum autoantibodies to cell surface determinants in multiple sclerosis: a flow cytometric study. Brain 2004;127:269-79.

11. Reindl M, Linington $C$, Brehm $U$, Egg R, Dilitz E, Deisenhammer $\mathrm{F}$, et al. Antibodies against the myelin oligodendrocyte glycoprotein and the myelin basic protein in multiple sclerosis and other neurological diseases: a comparative study. Brain 1999;122(Pt 11):2047-56.

12. Sellebjerg F, Christiansen M, Garred P. MBP, anti-MBP and anti-PLP antibodies, and intrathecal complement activation in multiple sclerosis. Mult Scler 1998;4:12731.

13. Khalil M, Reindl M, Lutterotti A, Kuenz B, Ehling R, Gneiss $C$, et al. Epitope specificity of serum antibodies directed against the extracellular domain of myelin oligodendrocyte glycoprotein: influence of relapses and immunomodulatory treatments. J Neuroimmunol 2006; $174: 147-56$
14. Lefranc D, Almeras L, Dubucquoi S, de Seze J, Vermersch P, Prin L. Distortion of the self-reactive IgG antibody repertoire in multiple sclerosis as a new diagnostic tool. J Immunol 2004;172:669-78.

15. Mathey E, Breithaupt C, Schubart AS, Linington C. Commentary: sorting the wheat from the chaff: identifying demyelinating components of the myelin oligodendrocyte glycoprotein (MOG)-specific autoantibody repertoire. Eur J Immunol 2004;34:2065-71.

16. Mantegazza R, Cristaldini $P$, Bernasconi $P$, Baggi $F$, Pedotti R, Piccini I, et al. Anti-MOG autoantibodies in Italian multiple sclerosis patients: specificity, sensitivity and clinical association. Int Immunol 2004;16:559-65.

17. Wang H, Munger KL, ReindI M, O'Reilly EJ, Levin LI, Berger $\mathrm{T}$, et al. Myelin oligodendrocyte glycoprotein antibodies and multiple sclerosis in healthy young adults. Neurology 2008;71:1142-6.

18. McDonald WI, Compston A, Edan G, Goodkin D, Hartung $\mathrm{HP}$, Lublin FD, et al. Recommended diagnostic criteria for multiple sclerosis: guidelines from the International Panel on the diagnosis of multiple sclerosis. Ann Neurol 2001:50:121-7.

19. Hauser SL, Waubant E, Arnold DL, Vollmer T, Antel J, Fox RJ, et al. B-cell depletion with rituximab in relapsingremitting multiple sclerosis. N Engl J Med 2008;358: 676-88.

20. Bech E, Jakobsen J, Orntoft TF. ELISA-type titertray assay of IgM anti-GM1 autoantibodies. Clin Chem 1994; 40:1331-4.

21. Bühlmann AG. Product Information anti-MAG IgM. http:// www. buhlmannlabs.ch/files/documents/core/Neuroimmunologie/german/EK-MAG_TF020Dweb.pdf. Accessed 2008.

22. Consortium U. The Universal Protein Resource (UniProt). Nucleic Acids Res 2008;36:D190-5.

23. Jain E, Bairoch A, Duvaud S, Phan I, Redaschi N, Suzek $B E$, et al. Infrastructure for the life sciences: design and implementation of the UniProt website. BMC Bioinformatics 2009;10:136.

24. Beniac DR, Luckevich MD, Czarnota GJ, Tompkins TA, Ridsdale RA, Ottensmeyer FP, et al. Three-dimensional structure of myelin basic protein. I. Reconstruction via angular reconstitution of randomly oriented single particles. J Biol Chem 1997;272:4261-8.

25. Rispoli $P$, Carzino R, Svaldo-Lanero T, Relini A, Cavalleri $O$, Fasano A, et al. A thermodynamic and structural study of myelin basic protein in lipid membrane models. Biophys J 2007;93:1999-2010. 